\title{
TURISMO Y CAMBIO SOCIAL EN SANTIAGO DE CUBA
}

\section{IDRIS M. IWAKI}

Licenciado en Sociología.

Universidad de Oriente-Santiago de Cuba.

\section{HÉCTOR O. BEATON}

Profesor asistente Departamento de Sociología.

Universidad de Oriente-Santiago de Cuba.

ERNESTO A. LÓPEZ

Profesor asistente Departamento de Sociología.

Universidad de Oriente-Santiago de Cuba.

\section{JAVIER M. FERRER}

Profesor titular Departamento de Trabajo Social y Servicios Sociales.

Universidad de Alicante.

\section{RESUMEN}

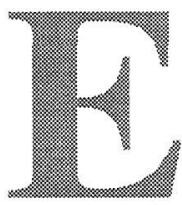

ste artículo presenta una aproximación a la influencia del turismo internacional en los cambios en la sociedad cubana. Se centra en el análisis de un espacio público representativo de la ciudad de Santiago de Cuba, el Parque Céspedes, en el que se profundiza sobre la aparición de un nuevo grupo social, «los jineteros», y su influencia sobre el resto de los grupos sociales que conviven en el Parque. Por último, se plantean unos interrogantes para la reflexión sobre el fenómeno.

\section{INTRODUCCIÓN}

Desde principios de los años noventa, como parte de la estrategia concebida por el Estado Cubano para el desarrollo económico del país en la difícil coyuntura producida por el derrumbe del campo socialista y el recrudecimiento del bloqueo impuesto a la isla, hemos asistido a un abrupto crecimiento de la actividad turística proyectada hacia el mercado internacional.

Estamos en presencia, sin duda, de un fenómeno sumamente complejo, cuya naturaleza contradictoria requiere una minuciosa atención. Se trata de un proceso que no sólo implica la inserción emergente y 
controvertida del socialismo cubano en el orden económico y político mundial, sino que, además, reconstituye de manera significativa el ser cultural de la isla.

Hoy es interés ineludible la evaluación de esta realidad y sus perspectivas. La preocupación es manifiesta en todas las instancias de la sociedad cubana, desde el discurso popular cotidiano hasta el discurso político oficial.

El impacto del turismo internacional en el organismo social cubano es abordado por especialistas de diversas disciplinas científicas, particularmente por investigadores de la esfera socio-humanística, aunque aún no se puede hablar más que de una aproximación cautelosa al fenómeno y de una visión no integral del mismo. En unas ocasiones se le evalúa a través de indicadores macro-económicos, en otras se analizan las consecuencias del auge del turismo en Cuba en el orden de los valores y la ideología a nivel social global. Se presta atención particular al referido problema también desde el punto de vista ecológico. Corto y estrecho camino han recorrido la sociología y la antropología en la exploración del impacto que está teniendo la irrupción del turismo en la vida de las comunidades y asentamientos poblacionales en que se enclavan las instalaciones destinadas a esa actividad ${ }^{1}$. Ofrecer una valoración acerca de los factores condicionantes del estado en que se encuentran las investigaciones sociales acerca de esta problemática en Cuba no constituye el objetivo de este artículo. Pretende tratar desde una perspectiva socio-antropológica el impacto del auge inusitado que ha tenido la actividad turística internacional en la sociedad de Santiago de Cuba, tomando como unidad de análisis un ámbito sui generis: una plaza pública; específicamente, el célebre Parque Céspedes, enclavado en el centro de la ciudad.

No contamos con referencia alguna de investigación de este tipo en espacios públicos como éste. Trabajos de esta naturaleza han sido realizados en otros países fundamentalmente por antropólogos estudiosos de la vida cotidiana en bares y barberías ${ }^{2}$.

1 El Gobierno y el Partido Comunista de la provincia de Santiago de Cuba promueven el proyecto multidisciplinar «Turquinito», en el ámbito de este proyecto se inserta esta investigación socio-antropológica acerca del impacto del turismo internacional.

? Una valiosa compilación de estudios de este tipo ofrecen PRAT, J,; MARTÍNEZ, U.; CONTRERAS, J.; MORENO, I. en «Antropología de los pueblos de España». Edit. Taurus Universitaria. Madrid, 1991. 


\section{EL PARQUE CÉSPEDES. UNIDAD DE ANÁLISIS}

«Toda sociedad contiene en su seno un número mayor o menor de réplicas de sí misma, más pequeñas y más simples» ${ }^{3}$. Esta sentencia de S.F. Nadel la asumimos como presupuesto general al considerar que el Parque Céspedes reproduce estructuralmente la realidad social en que se enmarca. La reflexión que aquí se desarrolla constituye un segmento de la investigación que se viene realizando desde aproximadamente un año acerca de la estructura social del Parque Céspedes, validándose la idea que la vida social en este ámbito se articula a partir de una estructura entendida como la red de relaciones estables entre los elementos que constituyen un sistema social que replica de manera concentrada y expresa cierta estructura de la sociedad total. Se parte de la percepción de la evolución del Parque Céspedes desde el punto de vista de los cambios ocurridos en su composición social y actividades a través de diferentes etapas de su historia.

El desarrollo del turismo internacional en Cuba ha influido en los cambios en la vida social induciendo la gestación de fenómenos que en el plano cultural también se refractan. Santiago de Cuba es la segunda ciudad en importancia de Cuba y uno de los principales polos de atracción turística. El Parque Céspedes es un centro histórico-cultural de extraordinario relieve en esta ciudad. La inserción del turismo internacional en Santiago de Cuba ha producido cambios significativos en la vida del Parque Céspedes que han deteriorado su imagen tradicional.

Se puede constatar el establecimiento en él de un nuevo grupo social. Podemos definir sus características y actividades fundamentales, a la vez que registramos el cambio operado en la imagen del Parque a partir de la valoración acerca de los fenómenos que han aparecido en él emiten otros grupos de población. Las consideraciones que aquí se exponen se apoyan en la información recopilada a través de las observaciones participantes y de las entrevistas realizadas, así como del estudio de valiosas fuentes biliográficas ${ }^{4}$. 


\section{UN NUEVO GRUPO SOCIAL. EL FENÓMENO DEL JINETERISMO}

Data de los noventa el asentamiento en el Parque Céspedes de un grupo de personas bien diferenciado de los grupos que a lo largo de muchos años han concurrido el lugar. Nos estamos refiriendo a los llamados «jineteros», que, según el diccionario UTEHA de México, la aceptación del infinitivo «jinetear» es: «andar a caballo, principalmente por los sitios públicos, alardeando de gala y primor... En México, obtener lucro o ganancia en forma ventajosa e indebida y en cosa ajena. Dícese especialmente del pagador que especula con el dinero a él confiado... Procurar los medios de sostenerse en una posición difícil; ofrecer resistencia con entereza a amenazas y peligros». El uso que en Cuba se hace de este vocablo es válido para designar la actividad del grupo citado.

La composición de este grupo no puede considerarse homogénea, dada la diferencia de los roles que desempeñan cada uno de los elementos que lo conforman, a pesar de esto, tienen una finalidad común y características afines. Se trata de un grupo cuyas edades oscilan entre los dieciséis y los treinta años. Las mujeres son generalmente negras o mestizas, en los hombres se nota un predominio de estas razas, pero en menor medida.

Entre sus atributos distintivos, está también la indumentaria que llevan. Su singular vestimenta los ha hecho fácilmente reconocibles, aunque, a decir verdad, últimamente su identificación resulta más difícil a causa del giro que ha experimentado la moda. La manera de vestir de estos individuos ofrece, en muchos casos, una imagen poco representativa de los componentes más auténticos de nuestra cultura.

Esto resulta contradictorio, dada la actividad a la que se dedican: la atracción del turista, con quien procuran sostener una relación a través de la cual le ofrecen una serie de servicios con el interés de conseguir el acceso a los beneficios del mercado que opera con las divisas libremente convertibles. Para el logro de este objetivo, recurren a medios moralmente reprobados por la casi totalidad de la población.

La mayoría de los entrevistados considera deplorable esta conducta, tanto por los medios como por los fines en que se funda. Muchas personas identifican el jineterismo con la prostitución. Algunas denominan «jinetero» sólo al también llamado «coatch», o sea, al individuo que asedia y captura al turista para facilitarle los servicios que éste demande. Podemos definir el jineterismo como toda una red de gente dispuesta a satisfacer al extranjero con tal de luchar por sus propios intereses, incluyendo el «botero» (taxista ilegal), el casero, el guía, la prostituta, el gígolo, el proxeneta, y hasta algunos empleados del turismo que se ponen en contubernio con toda esa gente. 
En efecto, si bien todas estas figuras desempeñan un rol específico, sería acertado considerarles como miembros de un mismo grupo, dada la estrecha relación que entre ellos necesariamente se establece en aras de una misma finalidad y por vías afines.

Así mismo, la opinión es casi de consenso respecto a que las actividades que acompañan al jineterismo se rigen por un marcado fin lucrativo, pues las necesidades que a costa de ellas satisfacen los jineteros no son prioritarias. Una anciana de casi ochenta años dice: «Yo no entiendo cómo esas muchachitas pueden venderse por un trapo, una Cocacola o por entrar en un hotel o en un restaurante. Es verdad que la cosa se ha puesto fea, pero no es para tanto».

Hay quienes consideran que algunos jineteros tratan de encontrar por sus medios el acceso al mercado de divisa para solventar necesidades más perentorias. Un intelectual de treinta y cuatro años dice: «Conozco a muchachones que viven en muy malas condiciones, hacinados en casa, que se encuentran en estado crítico y el ingreso económico de sus familias es sumamente reducido, también es cierto que, por lo general, esos jóvenes no dedican los beneficios de su actividad al mejoramiento de lo esencial de sus condiciones de vida, sino que prefieren satisfacer gustos y necesidades banales, tampoco están dispuestos a trabajar de verdad, prefieren luchar la vida de la manera más fácil».

Se trata, por lo general, de jóvenes desvinculados del trabajo y del estudio, que por su modus vivendi constituyen un grupo marginal en la sociedad cubana.

Todos los entrevistados coinciden en que estos elementos no desaparecieron totalmente con el proceso revolucionario, sino que en número mucho menor permanecieron desarraigados y velados desde 1959 . Ahora, la crítica situación económica del país ha restablecido esos males que con el fuerte desarrollo del turismo internacional han tomado mayor fuerza.

Los grupos anteriormente citados comienzan a frecuentar el Parque Céspedes a partir de los años sesenta a pesar de la repulsa popular. Hoy toda su actividad gira en torno a la presencia del turista en la vida nacional. Desde los años sesenta aparecen en el Parque Céspedes individuos que perseguían al turista con el propósito de intercambiar mercancías. Le ofrecían artículos generalmente exóticos, del folklore nacional a cambio de ropa o equipos electrodomésticos, raramente lo hacían por dinero, dado el limitado acceso que tenían entonces al mercado de divisa.

Por aquellos años, eran los soviéticos los que pululaban por Santiago de Cuba y, en menor escala, los marineros, sobre todo los griegos, que atracaban en el puerto de la ciudad.

Un grupo de adultos mayores, asiduos del Parque durante más de treinta años, refieren que en la etapa del capitalismo las prostitutas no 
tenían cabida en este lugar: «Sólo podían ejercer su oficio en determinados establecimientos como la Casa Amada, la Casa Lola o en bares como el Flamingo, el mar Init o el Cabilla, entre otros. Existía, además, la llamada Zona de Tolerancia. La Ley proscribía y castigaba severamente a las prostitutas que se exhibieran en lugares públicos. Ellas se consideraban a sí mismas y eran vistas por todos como personas de la más baja categoría. Hoy, en cambio, andan por doquier, presumiendo de sus facilidades impunemente. Se les ve en el Parque Céspedes y en los hoteles persiguiendo a los extranjeros para tumbarles el "Fao"...".

Resulta interesante el hecho de que este grupo, heterogéneo según se ha reseñado, se haya convertido en un elemento estable en el Parque, haciéndose espacio propio y que, además, está coexistiendo con los grupos de naturaleza distinta a la suya que personifican su historia. Ello implica la concurrencia en los últimos años de un proceso de recualificación de la vida del Parque, que consideramos ilustrativo de lo que está sucediendo en otros ámbitos y a escala en toda la sociedad.

La manera en que cohabitan en el Parque Céspedes grupos tan distintos, sociológicamente hablando, como los ancianos jubilados y los jineteros, por ejemplo, nos hace pensar que hay un cierto nivel de tolerancia individual y colectiva con relación al jineterismo. Según hemos podido corroborar a través de las entrevistas realizadas, existe cierta ambivalencia de posición desde el punto de vista moral hacia estas actividades y los fenómenos que acompañan, por otra parte, también se percibe una justificación tácita de los mismos al considerárseles como el resultado inevitable e insuperable de la situación económica del país. Un estudiante universitario plantea: «Eso no hay quien lo pare». Un joven intelectual sentencia: «Esa es la otra faceta del turismo; el turista viene de un mundo distinto al nuestro y trae consigo una parte de aquella realidad».

El deterioro de la imagen del Parque Céspedes a partir de la inserción y desarrollo del turismo internacional en el país y, particularmente, en Santiago de Cuba, se hace expreso no sólo en la valoración que emiten los entrevistados acerca de los jineteros sino, además, en el hecho de que muchas personas que fueron habituales visitantes del Parque se hayan retirado del mismo, con la excepción de los más ancianos, en quienes lógicamente predomina la fuerza de la costumbre. Para los más jóvenes, el Parque no parece ser un centro de atracción importante, a lo que seguramente ha contribuido la mala reputación que éste ha ido ganando. Una muchacha de veintitrés años explica: «AI Parque ya no se puede ir. Antes uno iba porque había música, baile, era un lugar tranquilo y alegre... Aunque allí siempre hubo ciertos elementos, eran pocos y no molestaban... Ahora de sólo pasar por allí te pones tensa por temor a que te vayan a creer jinetera... La policía está persi- 
guiendo al jinetero y a todo lo que se parezca... Por eso, yo ni paso por allí, ni dejaría que mis hijos lo hicieran».

Una señora de ochenta años manifiesta: «Yo no voy al Parque Céspedes..., y a mis nietos se lo prohíbo. El Parque se ha convertido en un antro de perdición». Un anciano que lleva frecuentando el Parque Céspedes treinta y cinco años comenta: «Antes el Parque Céspedes era un centro prestigioso, al que las personas acudían placenteramente. En él se exhibían las buenas costumbres. Hoy la cosa es muy distinta, yo no sé qué está pasando».

Un señor de unos sesenta años se refiere a la década de los cincuenta: «En aquella etapa ni la prostituta ni el homosexual, y tampoco los indigentes, podían permanecer en el Parque».

Actualmente, la presencia de los niños en este centro se hace cada vez menor, en la medida en que los maestros y padres que habitualmente los llevaban allí a pasear, jugar y dar vueltas por dentro del Parque en carros tirados por chivos, van tomando conciencia del peligro que se corre en un ámbito tan viciado. Los agentes del orden interior sugieren a los maestros que no traigan a los escolares al Parque, ya que el ambiente no es apropiado para ellos.

Es evidente que entre los elementos que concurren en el Parque Céspedes, sólo los policías mantienen una relación de rechazo absoluto y explícito con los jineteros, los enfrentan a pesar de que el Estado no ha dispuesto regulación jurídica alguna a tal efecto. El antagonismo entre ambos grupos enrarece el clima del lugar, lo que provoca no sólo el desplazamiento temporal de los jineteros hacia otros puntos donde serán igualmente hostigados, sino también que otros grupos se retiren del mismo, tal vez para no regresar.

La vida del Parque se ha desenvuelto de tal modo durante los últimos años que su situación actual podría parecer normal y natural, pero cuando la policía ocupa el Parque se respira una atmósfera artificial. Una muchacha de veintitrés años nos decía: «¿Ustedes se imaginan que estando yo en el Parque se me aproxime un turista, o que casualmente se siente a mi lado? Seguro que me pide el carnet de identidad y hasta me fichan. Aunque después te pidan disculpas, es mejor no pasar el mal rato y el bochorno en público. Por eso, a mí no se me ha perdido nada en esa zona»s.

Otra joven de la misma edad agregaba: «Entonces el que tiene amistad con algún extranjero no sabe qué hacer, teme andar por la calle con él o invitarlo a su casa porque puede ser tildado de jinetero... La gente ve mal cualquier tipo de relación con los extranjeros...». 


\section{INTERROGANTES PARA LA REFLEXIÓN}

Estamos en presencia de un fenómeno muy complejo en todos los órdenes y que debe ser tratado con responsable conciencia de sus múltiples y profundos riesgos.

Diversos son los interrogantes que suscitan estos hechos, cuya ulterior evolución es difícil vislumbrar en estos días. Es necesario profundizar en la investigación socio-humanística sobre la realidad reflejada.

El desarrollo de la actividad turística en Cuba replantea la situación del Estado no sólo en el orden económico y político mundial, sino además en el concierto cultural de los pueblos. ¿Cómo conciliar este proceso con el mantenimiento del proyecto social cubano en la actual coyuntura? ¿Cómo son las perspectivas de la evolución que habrá de experimentar los preceptos morales, estéticos e ideológicos del pueblo cubano como resultado del intercambio con otras culturas? ¿Será posible controlar el impacto del turismo internacional en el país a través de una política de oferta depurativa con respecto a las demandas del turista?

¿Cuál será la historia futura del Parque Céspedes, cuál su rol en la ruta turística del Caribe? ¿Quiénes habitarán a su sombra el corazón de Santiago de Cuba?

Hemos de procurar que, en un futuro no tan lejano, estas líneas constituyan no más que pasajes de un pueblo que franqueó con decoro los desafíos de este tiempo. 